\title{
Comparative Study of Ti-xCr-3Sn Alloys for Biomedical Applications
}

\author{
Abdul Wadood $^{1, *}$, Tomonari Inamura ${ }^{1}$, Hideki Hosoda ${ }^{1}$ and Shuichi Miyazaki ${ }^{2}$ \\ ${ }^{1}$ Precision and Intelligence Laboratory, Tokyo Institute of Technology, Yokohama 226-8503, Japan \\ ${ }^{2}$ Institute of Materials Science, University of Tsukuba, Tsukuba 305-8573, Japan
}

In order to replace toxic nickel element from NiTi biomaterials, $\mathrm{Ti}-\mathrm{Cr}$ and $\mathrm{Ti}-\mathrm{Cr}-X$ alloys are also new nickel free titanium based alloys for biomedical applications. In this study, comparative study of Ti- $x \mathrm{Cr}-3 \mathrm{Sn}(x=4,5,6,7,8$ and 9 mol\%) alloys was carried out. Ti-4Cr-3Sn and Ti5Cr-3Sn alloys were composed of $\alpha^{\prime}$ martensitic phase (hcp) and other alloys with 6, 7, 8 and 9 mol\% $\mathrm{Cr}$ were single $\beta$ phase at room temperature. Among the developed alloys, Ti-6Cr-3Sn alloy showed maximum fracture strain, maximum shape memory effect, maximum pseudoelastic response and minimum hardness and minimum yield stress due to transformation of metastable $\beta$ phase to stress induced martensite during mechanical loading. Vickers hardness and UTS has increased and fracture strain has decreased with greater than 6 mol\% addition of chromium in $\mathrm{Ti}-x \mathrm{Cr}$-3Sn alloys due to solid solution strengthening, $\beta$ phase stabilization and slip as dominant deformation mechanism. It is concluded that among the developed $\mathrm{Ti}-x \mathrm{Cr}-3 \mathrm{Sn}$ alloys, Ti-6Cr-3Sn alloy is hopeful new alloy for biomedical applications. [doi:10.2320/matertrans.M2011153]

(Received May 20, 2011; Accepted June 30, 2011; Published August 25, 2011)

Keywords: titanium-chromium-tin, mechanical properties, pseudoelasticity, shape memory effect

\section{Introduction}

Although equiatomic Ti-Ni alloy (nitinol) has been widely applied as implant material due to excellent mechanical and shape memory properties. However nitinol contains toxic nickel element. ${ }^{1,2)}$ Recently, $\beta$ type Ti alloys composed of non-toxic elements have attracted much attention as potential biomedical shape memory and superelastic material. ${ }^{3-6)}$ Commercially pure titanium and titanium alloys have been popularly used in many medical applications due to their light weight, excellent mechanical performance and biocompatibility. ${ }^{4,5)}$ Pure titanium is not suitable for all purposes due to high melting point, high reactivity with oxygen and absence of shape memory and superelastic properties, many titanium alloys have been developed for biomedical and engineering applications and their properties have been evaluated mainly to improve the biocompatibility and biofunctionality as implant material. ${ }^{6-11)}$

Advantages of $\beta$ titanium alloys over $\alpha$ or $(\alpha+\beta)$ alloys are their lower modulus and better formability. ${ }^{7)}$ The relatively low modulus of $\beta$ titanium alloys that can reduce the "stress-shielding" effect ${ }^{8,9)}$ has also drawn much attention to researchers. For biomedical applications, recently a systematic investigation has been carried out by our group for Ti-Nb and Ti-Mo alloys. ${ }^{10-15)} \beta$ type Ti-based alloys exhibit $\beta$ phase (disordered bcc) at higher temperatures and $\alpha$ phase (hcp, $c / a=1.587$ ) at lower temperatures. $\beta$ type titanium alloys also exhibit three metastable phases, $\alpha^{\prime}$ (hcp), $\alpha^{\prime \prime}$ (orthorhombic) and $\omega$ (hexagonal, $c / a=0.68$ ) phases. $^{16)}$ Quenching from $\beta$ phase leads to the transformation from the parent $\beta$ phase to either hexagonal martensite $\left(\alpha^{\prime}\right)$ or orthorhombic martensite $\left(\alpha^{\prime \prime}\right)$ depending on solute content. It has been reported that the reverse transformation from $\alpha^{\prime \prime}$ (orthorhombic) phase to the $\beta$ phase causes shape recovery to appear. ${ }^{17-19)} \mathrm{Ti}-\mathrm{Cr}$ is also hopeful alloy system for biomedical applications and there are some reports on

*Graduate Student, Tokyo Institute of Technology mechanical properties of Ti-Cr ${ }^{20,21)}$ and Ti-Cr- $X$ alloys. ${ }^{22-25)}$ Selection of Ti-Cr-Sn alloy system was due to $\beta$ phase stabilizing effect of $\mathrm{Cr}$, low melting points of $\mathrm{Cr}$ and $\mathrm{Sn}$ as compared to other $\beta$ phase stabilizing elements and solid solution strengthening effect of $\mathrm{Cr}$ and $\mathrm{Sn}$ (atomic radius: $\mathrm{Cr}=0.126 \mathrm{~nm}, \mathrm{Sn}=0.158 \mathrm{~nm}, \mathrm{Ti}=0.146 \mathrm{~nm}$ ). It is mentioned that the deformation behavior of binary $\mathrm{Ti}-x \mathrm{Cr}$ alloys is composition dependent. ${ }^{26)}$ Kusano et al. ${ }^{25)}$ of our research group reported that addition of $3 \mathrm{~mol} \% \mathrm{Sn}$ in Ti-5Cr binary alloy is effective in improving cold workability and decreasing hardness most probably due to suppression of $\omega$ phase precipitation. So in present investigation, $\mathrm{Ti}-\mathrm{xCr}-3 \mathrm{Sn}$ alloys were selected for investigation of mechanical, shape memory and pseudoelastic properties. Sn is also biocompatible and $\mathrm{Sn}$ addition is capable of improving the cold workability of titanium alloys. ${ }^{19)}$ Maeshima et al. ${ }^{27)}$ reported that $\mathrm{Sn}$ addition is effective in improving the shape memory effect and $\mathrm{Sn}$ additions suppress omega $(\omega)$ phase precipitation in Ti-Mo-Sn alloys. Sn addition is also effective in decreasing martensitic transformation start temperature (Ms) and stabilizing $\beta$ phase in $\mathrm{Ti}-\mathrm{Nb}-\mathrm{Zr}-\mathrm{Sn}^{28)}$ and $\mathrm{Ti}-\mathrm{Nb}-\mathrm{Sn}^{29)}$ alloys.

\section{Experimental Procedure}

99.99\% pure titanium, chromium and tin metals were melted four times into ingots using nonconsumable $\mathrm{W}$ electrode type arc-melting furnace in an $\mathrm{Ar}-1 \% \mathrm{H}_{2}$ atmosphere, being flipped over after each melting step in order to ensure homogeneity in composition. The mass loss after melting was negligible (less than $0.2 \%$ ) for all the compositions. After vacuum-encapsulating into quartz tubes, these ingots were homogenized at $1273 \mathrm{~K}$ for $7.2 \mathrm{ks}$ and then quenched into water. Then the ingots were cold-rolled to $96 \%$ in thickness reduction. Cold rolling reduction per pass was $2 \%$ or less. Final thickness of specimen after cold rolling was about $400 \mu \mathrm{m}$. In case of Ti-4Cr-3Sn and Ti-5Cr-3Sn ingots, $96 \%$ rolled sheet could not be obtained due to poor ductility, then part of the ingot was cut and used for analysis. Other 
alloy compositions of Ti- $x \mathrm{Cr}-3 \mathrm{Sn}(x=6,7,8$ and $9 \mathrm{~mol} \%)$ were successfully cold rolled to $96 \%$ rolling reduction. Cold rolled specimens were cut into desired shapes using diamond cutting wheel. Then specimens were mechanically polished, wrapped in titanium foils and solution-treated at $1273 \mathrm{~K}$ for $1.8 \mathrm{ks}$ and quenched into water. Solution treated specimens were mechanically polished and mechanical testing (Vickers, tensile and cyclic test) was carried out. Electropolishing at about $223 \mathrm{~K}$ was carried out before microscopy. Solution of $\mathrm{HClO}_{4}, \mathrm{CH}_{3} \mathrm{OH}$ and butanol in a ratio of $1: 6: 10$ was used as an electrolyte for electropolishing.

Phase constitution was investigated using XRD and an optical microscopy. $\theta-2 \theta$ XRD measurement was made at room temperature (RT) from $30^{\circ}$ to $90^{\circ}$, step size of $0.02^{\circ} /$ $\sec$ in $2 \theta$ using $\operatorname{CuK} \alpha$ radiation. The quantitative phase analysis was performed with an X'Pert Highscore software package. Chemical etching was done for optical microscopy using a solution of $15 \% \mathrm{HCl}, 8 \% \mathrm{HNO}_{3}$ and $77 \% \mathrm{H}_{2} \mathrm{O}$ (distilled water). Mechanical properties were evaluated using tensile tests and cyclic loading-unloading tests and Vickers hardness tests at room temperature. For tensile/cyclic tests, the specimens were cut along the rolling direction of $0.2-$ $0.3 \mathrm{~mm}$ in thickness, $2 \mathrm{~mm}$ in width and $20 \mathrm{~mm}$ in length. An Instron-type Shimadzu AG-1 kN Tensile Machine was used and $5 \times 10^{-4} / \mathrm{s}$ strain rate was selected. Vickers hardness tests were performed by seven-point measurements using Akashi HM-102 Micro Vickers Hardness Testing Machine with $0.3 \mathrm{~kg}$ load and $10 \mathrm{~s}$ holding time. Shape memory effect was measured by first bending specimen by $180^{\circ}$ using $6 \mathrm{~mm}$ diameter mandrel and then unloaded. Deformed specimen was heated to higher temperature for shape recovery using cigerete lighter. Recovery ratio due to shape memory effect was also calculated.

\section{Results and Discussion}

\subsection{Phase analysis and cold workability}

Ti-4Cr-3Sn and Ti-5Cr-3Sn alloys were cracked after $34 \%$ and $39 \%$ cold rolling reduction respectively and thus these two alloys were unable to cold-roll to $96 \%$ reduction. The other compositions with $6,7,8$ and $9 \mathrm{~mol} \% \mathrm{Cr}$ were successfully cold rolled to $96 \%$ reduction. Figure 1 shows the XRD and Fig. 2 shows the optical microscopic analysis of developed alloys. $\alpha^{\prime}$ (hcp martensite) phase was detected for Ti-4Cr-3Sn and Ti-5Cr-3Sn alloys. So for these two compositions, $\beta$ phase that was stable at homogenization temperature $(1273 \mathrm{~K})$ transformed to hexagonal close packed hcp martensite upon quenching. It was analyzed from optical microscopic results (Fig. 2) that amount of $\alpha^{\prime}$ (hcp martensite) phase was lower in $\mathrm{Ti}-5 \mathrm{Cr}-3 \mathrm{Sn}$ alloy as compare to Ti$4 \mathrm{Cr}-3 \mathrm{Sn}$ alloy due to $\beta$ phase stabilization effect of $\mathrm{Cr}$. It was also analyzed that $\beta$ phase was stable above $5 \mathrm{~mol} \% \mathrm{Cr}$ additions (Fig. 1 and Fig. 2) in current alloy system. $\mathrm{Cr}$ addition was effective in enhancing the cold workability of Ti- $x$ Cr-3Sn alloys as given in Table 1 .

\subsection{Mechanical properties}

Ti-4Cr-3Sn and Ti-5Cr-3Sn alloys were not tensile tested because the rolled sheet could not be obtained due to poor cold workability. Figure 3 shows the stress-strain curves of
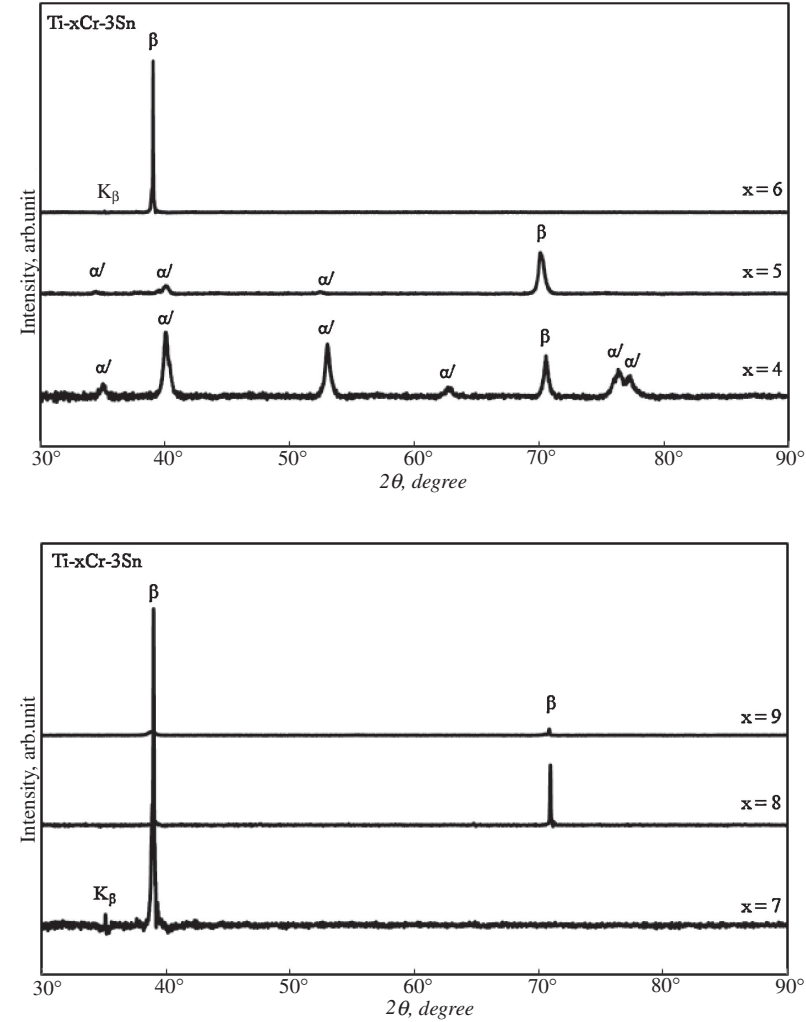

Fig. 1 XRD analysis of Ti- $x$ Cr-3Sn alloys.

Table 1 Cold workability of Ti- $x \mathrm{Cr}-3 \mathrm{Sn}$ alloys.

\begin{tabular}{cccc}
\hline $\begin{array}{c}\text { Alloy } \\
\text { Composition }\end{array}$ & $\begin{array}{c}\text { Cold Rolling } \\
\text { Reduction }(\%)\end{array}$ & $\begin{array}{c}\text { Cold } \\
\text { workability }\end{array}$ & $\begin{array}{c}\text { Apparent phase by } \\
\text { XRD analysis }\end{array}$ \\
\hline Ti-4Cr-3Sn & 34 & Not good & $\alpha^{\prime}$ \\
\hline Ti-5Cr-3Sn & 39 & Not good & $\alpha^{\prime}$ \\
\hline Ti-6Cr-3Sn & 96 & Very good & $\beta$ \\
\hline Ti-7Cr-3Sn & 96 & Very good & $\beta$ \\
\hline Ti-8Cr-3Sn & 96 & Very good & $\beta$ \\
\hline Ti-9Cr-3Sn & 96 & Very good & $\beta$ \\
\hline
\end{tabular}

Ti- $x$ Cr-3Sn $(x=6,7,8$ and 9 mol\%) developed alloys. Results of UTS and $0.2 \%$ proof stress of developed alloys are given in Fig. 4. Ti-6Cr-3Sn alloy exhibited maximum ductility of $41 \%$ fracture strain and relatively low yield stress $(300 \mathrm{MPa})$. This ductile behavior was due to transformation of metasble $\beta$ phase to stress induced martensite $\left(\alpha^{\prime \prime}\right)$ during mechanical loading (Fig. 7) and due to twinning deformation mode to accommodate deformation strains as shown by arrows in Fig. 5. It was also found from optical microscopic analysis given in Fig. 5 and XRD analysis given in Fig. 7 that both the stress induced martensitic transformation and twinned region have increased with increasing applied strain from $2 \%$ to $41 \%$ at fracture for Ti-6Cr-3Sn alloy.

Ti-6Cr-3Sn and Ti-7Cr-3Sn alloys exhibited characteristic serration behavior (see Fig. 3 and Fig. 10). Since Ti-6Cr-3Sn and $\mathrm{Ti}-7 \mathrm{Cr}-3 \mathrm{Sn}$ alloys also exhibited shape memory effect and pseudoelastic response that will be explained later, the serration behavior was related to stress induced martensitic 

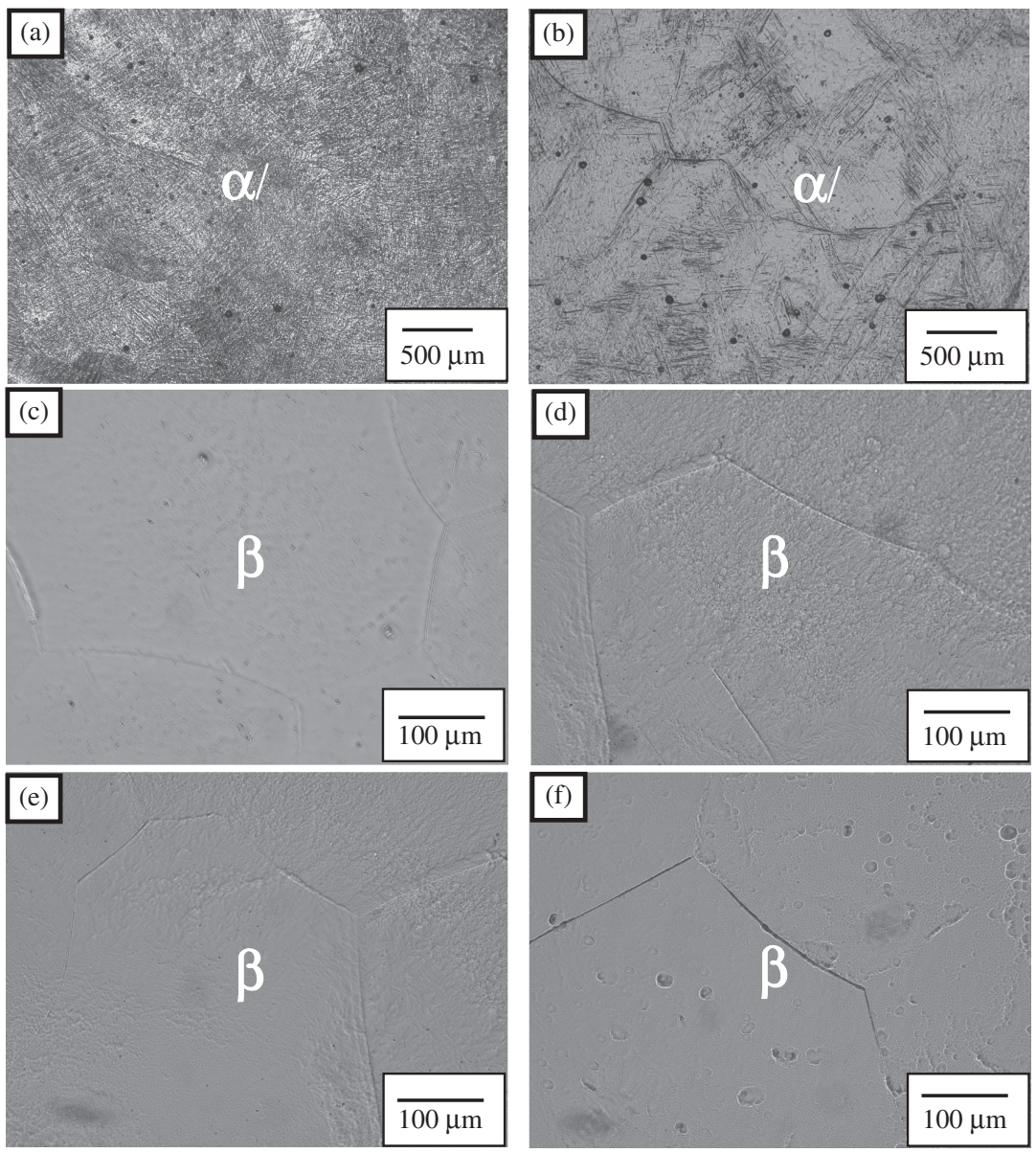

Fig. 2 Optical microscopy of Ti- $x$ Cr-3Sn alloys. (a) $x=4$ (b) $x=5$ (c) $x=6$ (d) $x=7$ (e) $x=8$ (f) $x=9$.
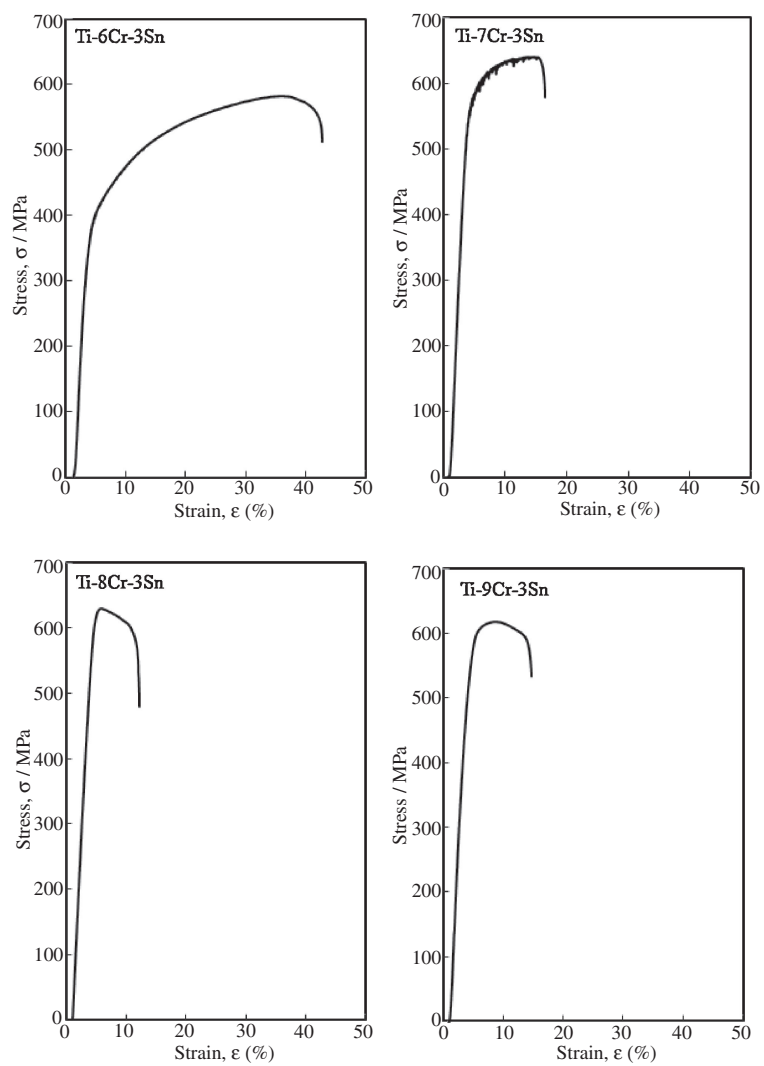

Fig. 3 Stress-strain curves of Ti- $x \mathrm{Cr}-3 \mathrm{Sn}$ alloys.

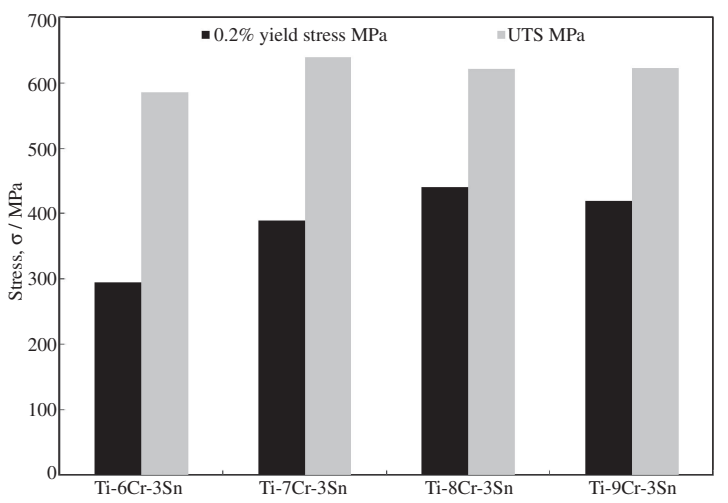

Fig. 4 UTS and $0.2 \%$ yield stress of Ti- $x$ Cr-3Sn alloys.

transformation. Serration behavior was also analyzed in metastable $\beta$ Ti-Nb-Al alloys. ${ }^{30)}$ From XRD analysis of deformed Ti-9Cr-3Sn alloy specimen (Fig. 8), it was investigated that $\beta$ phase did not transform to stress induced martensite and $\beta$ phase remained stable during mechanical loading.

It was also investigated from optical microscopy (Fig. 6) and XRD (Fig. 8) analyses of Ti-9Cr-3Sn alloy before and after tensile deformation, that both twinning deformation mode and stress induced martensitic transformation were absent. This also showed that slip was dominant deformation mechanism for Ti-9Cr-3Sn alloy. Comparing Fig. 5 and 

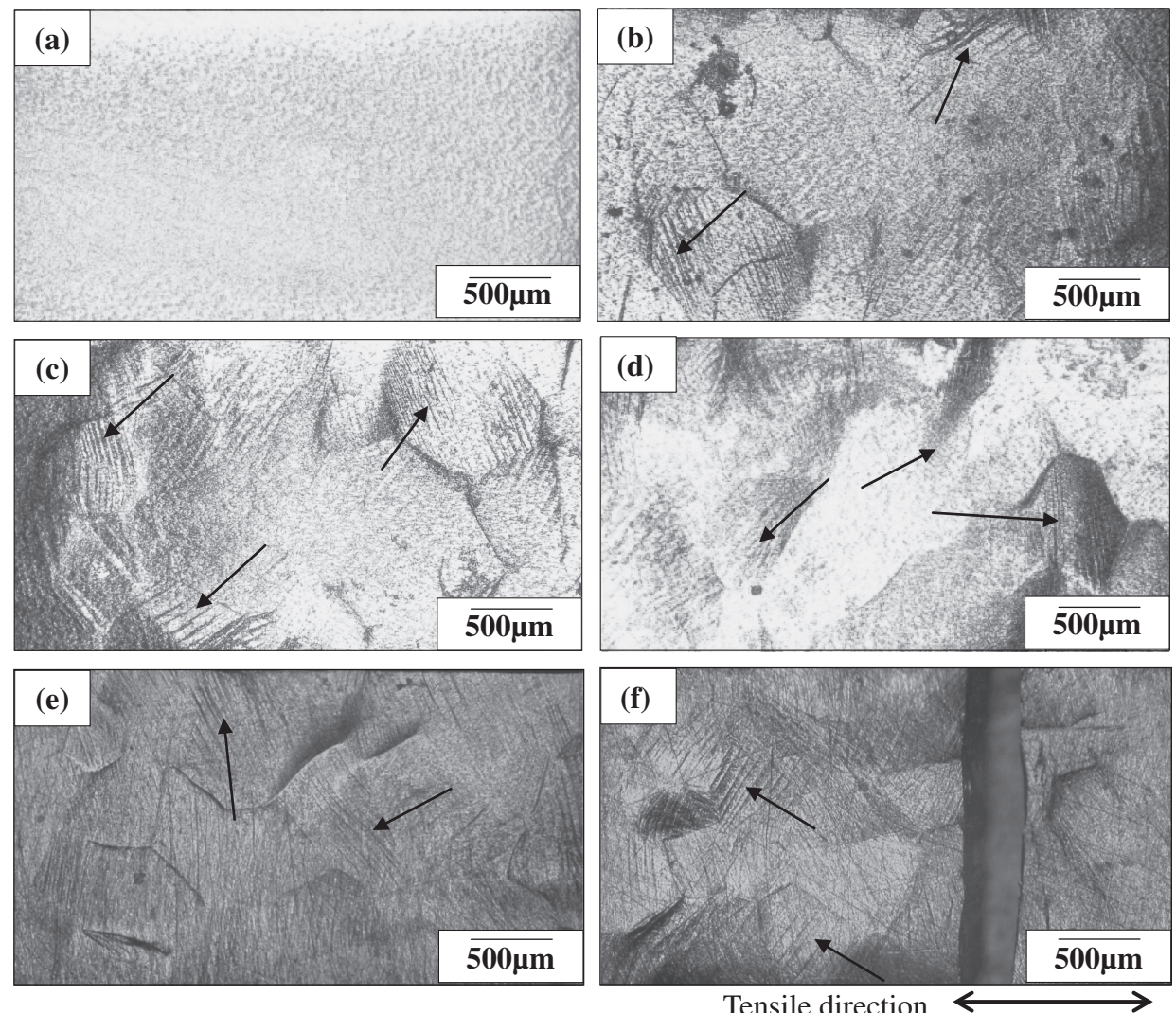

Fig. 5 Optical microscopy of Ti-6Cr-3Sn alloy before and after tensile deformation (un-etched). (a) before deformation (b) after $2 \%$ strain (c) after $5 \%$ strain (d) after $8 \%$ strain (e) after $41 \%$ fracture strain (f) fracture surface.
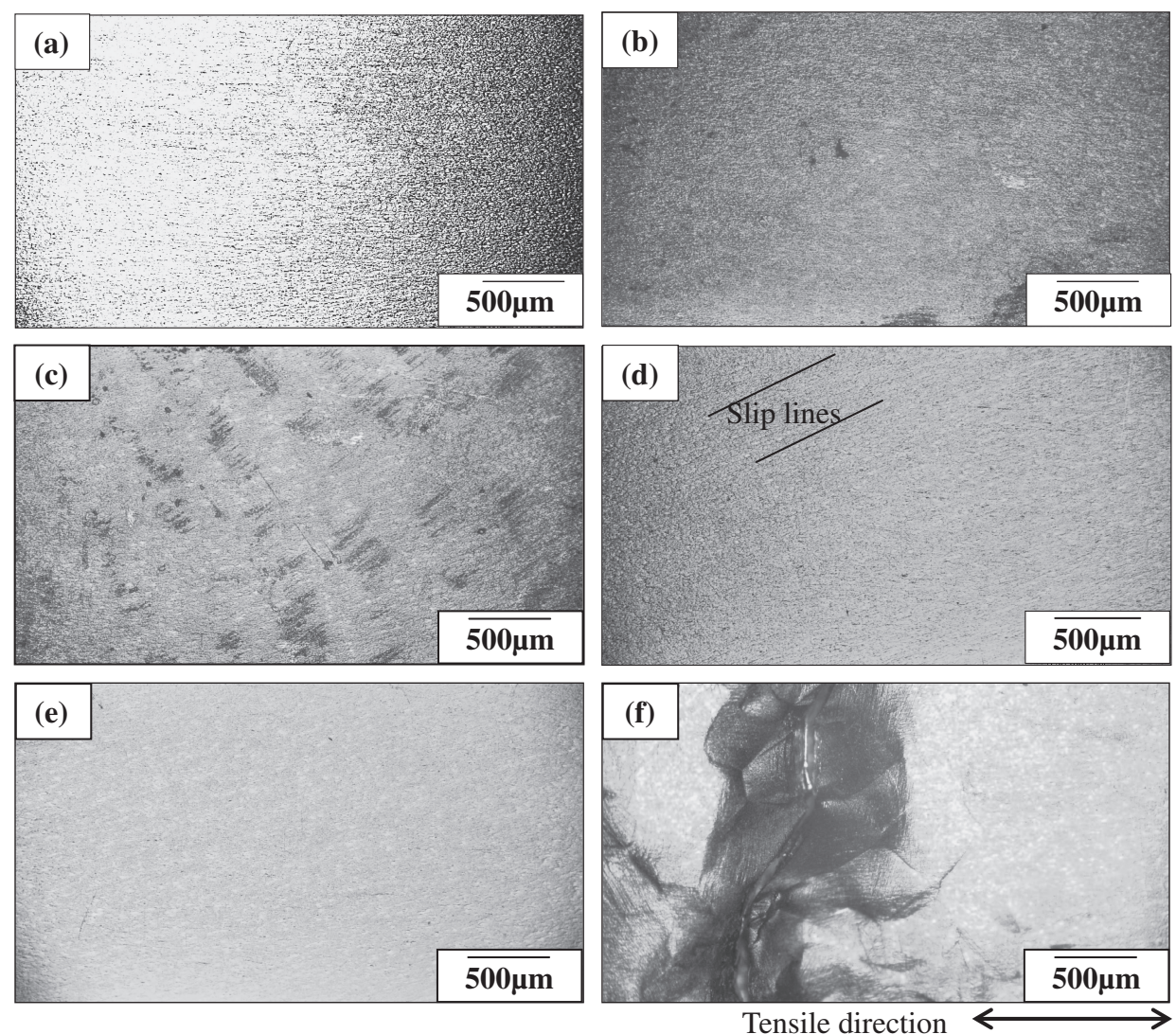

Fig. 6 Optical microscopy of Ti-9Cr-3Sn alloy before and after tensile deformation (un-etched). (a) before deformation (b) after $2 \%$ strain (c) after 5\% strain (d) after $8 \%$ strain (e) after 13\% fracture strain (f) fracture surface. 

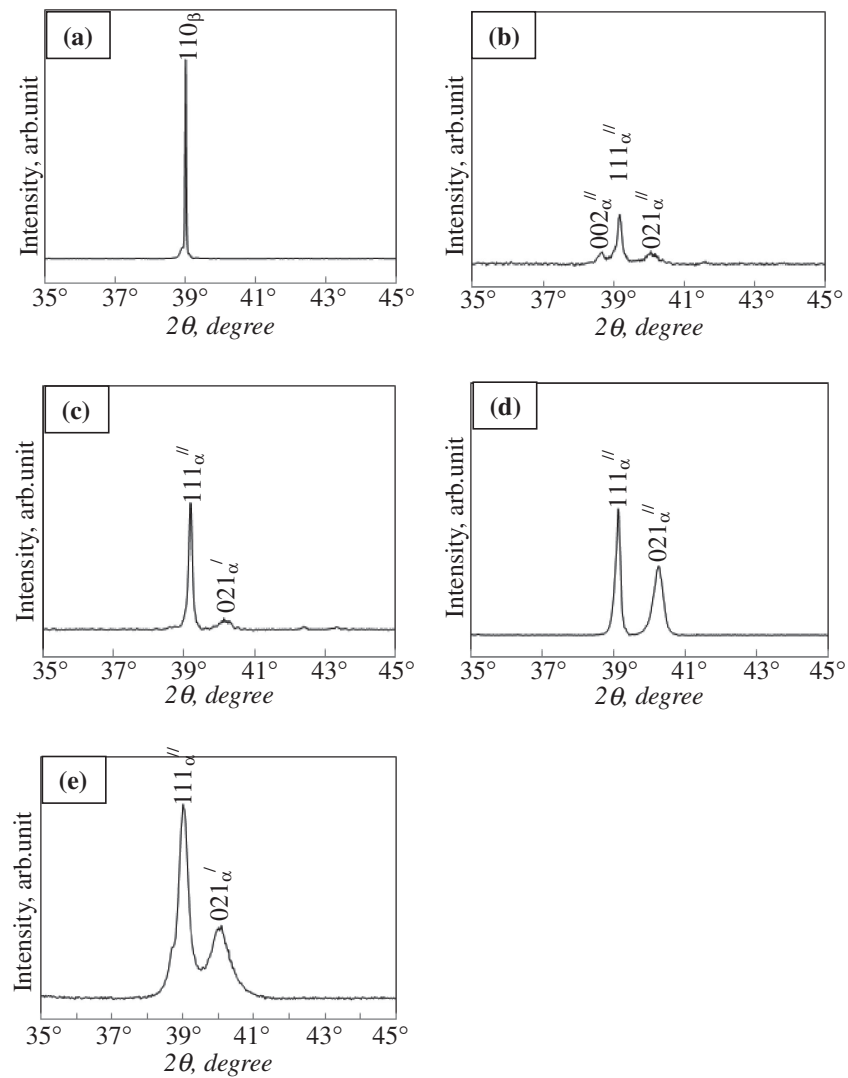

Fig. 7 XRD analysis of Ti-6Cr-3Sn alloy before and after tensile deformation. (a) before deformation (b) after $2 \%$ strain (c) after 5\% strain (d) after $8 \%$ strain (e) after $41 \%$ fracture strain.

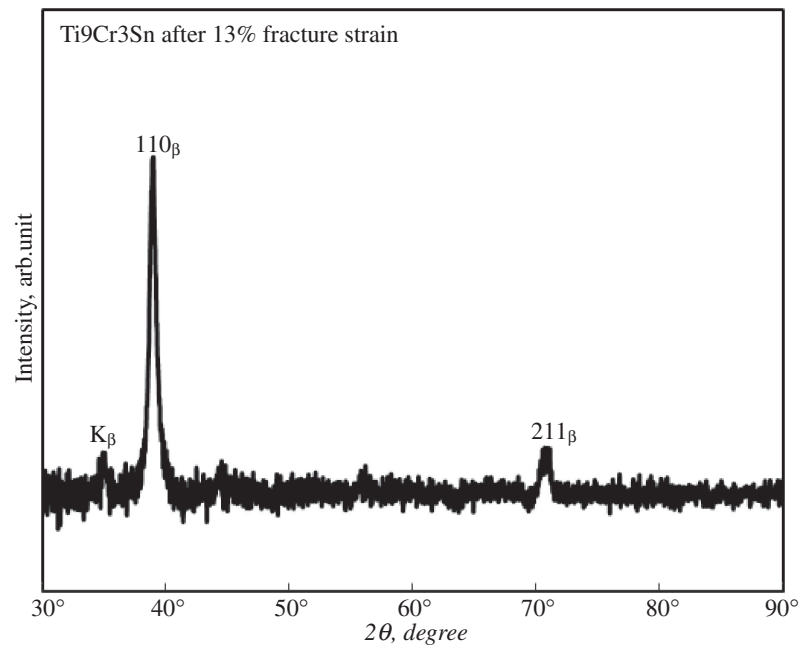

Fig. 8 XRD after tensile deformation of Ti-9Cr-3Sn alloy.

Fig. 6, twinning was analyzed for Ti-6Cr-3Sn alloy while slip deformation was analyzed for Ti-9Cr-3Sn alloy. This also showed that twinned deformation mode has changed to slip deformation mode with increasing chromium content from $6 \mathrm{~mol} \% \mathrm{Cr}$ to $9 \mathrm{~mol} \% \mathrm{Cr}$ in $\mathrm{Ti}-\mathrm{xCr}-3 \mathrm{Sn}$ alloys due to $\beta$ phase stabilization. Comparing Fig. 7 and Fig. 8, it was investigated that $\beta$ phase was in metastable state for Ti-6Cr-3Sn alloy while $\beta$ phase was in stable state for Ti-9Cr-3Sn alloy.

From results of Fig. 3 and Fig. 4, it was analyzed that UTS and yield stress have increased and fracture strain has

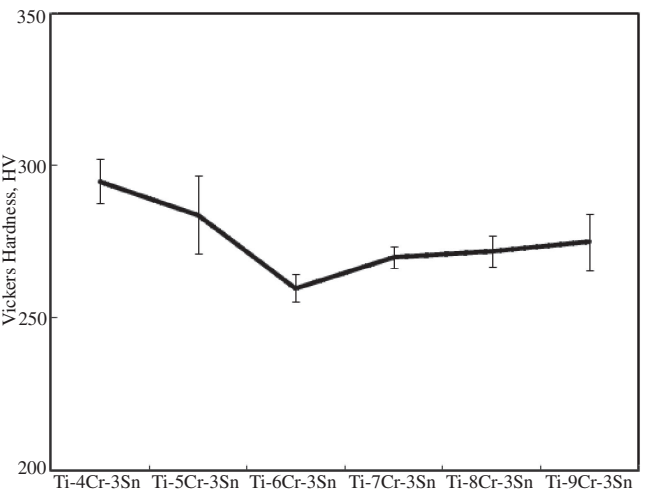

Fig. 9 Vickers hardness results of Ti- $x \mathrm{Cr}-3 \mathrm{Sn}$ alloys.

decreased with greater than $6 \mathrm{~mol} \%$ addition of $\mathrm{Cr}$ content due to solid solution strengthening, $\beta$ phase stabilization (Fig. 8) and also due to slip (Fig. 6) as dominant deformation mechanism instead of twinning (Fig. 5). So from tensile test results, it is concluded that $\mathrm{Ti}-6 \mathrm{Cr}-3 \mathrm{Sn}$ developed alloy was in metastable $\beta$ state and excellent ductility was due to transformation of metastable $\beta$ phase to stress induced martensite and due to twinning deformation mode during mechanical loading. ${ }^{18)}$

Vickers hardness test results are given in Fig. 9. Ti-4Cr3Sn alloy exhibited highest hardness among the developed Ti- $x$ Cr-3Sn alloys due to hcp martensite $\left(\alpha^{\prime}\right)$ dominant phase as confirmed from XRD (Fig. 1) and optical microscopy (Fig. 2) results. Hardness values of Ti- $x \mathrm{Cr}-3 \mathrm{Sn}$ alloys have decreased up to $6 \mathrm{~mol} \%$ addition of $\mathrm{Cr}$ content due to increase in the amount of $\beta$ phase and also due to transformation of metastable $\beta$ phase to stress induced martensite during indentation. Increase in hardness with greater than $6 \mathrm{~mol} \% \mathrm{Cr}$ additions was again related to solid solution strengthening effect and also due to $\beta$ phase stabilization (Fig. 8). Such kind of hardness trend was also mentioned by $\mathrm{S}$. Doi et al. ${ }^{31)}$ for Ti-Cr binary alloys. All $\beta$ phase peaks were not detected in Fig. 8 due to deformation texture ${ }^{14,32)}$ as deformed specimen of Ti-9Cr-3Sn alloy was used for phase analysis.

\subsection{Pseudoelasticity}

Stress-strain curves of cyclic loading-unloading tensile tests for first five cycles with constant strain increment per cycle are given in Fig. 10. Ti-4Cr-3Sn and Ti-5Cr-3Sn alloys were not tested because the rolled sheet could not be obtained due to poor cold workability. Purpose of these cyclic loading-unloading tests was to analyze the pseudoelastic behavior of Ti- $x \mathrm{Cr}-3 \mathrm{Sn}(x=6,7,8$ and $9 \mathrm{~mol} \%)$ alloys. Among the developed alloys, Ti-6Cr-3Sn alloy showed maximum plastic recovered strain (1\%) related to pseudoelasticity (Fig. 10 and Fig. 11) due to reversion of some fraction of deformed martensite to twinned martensite (martensite reorientation). ${ }^{33)}$ Small plastic recovered strain was most probably due to slip along with twinning and also due to martensite reorientation during unloading ${ }^{34)}$ as compare to phase transformation from stress induced martensite to partent $\beta$ phase. ${ }^{28)}$

It was already mentioned that $\mathrm{Ti}-6 \mathrm{Cr}-3 \mathrm{Sn}$ alloy showed excellent ductility ( $41 \%$ fracture strain) due to transformation of metastable $\beta$ phase to stress induced martensite (Fig. 7) 

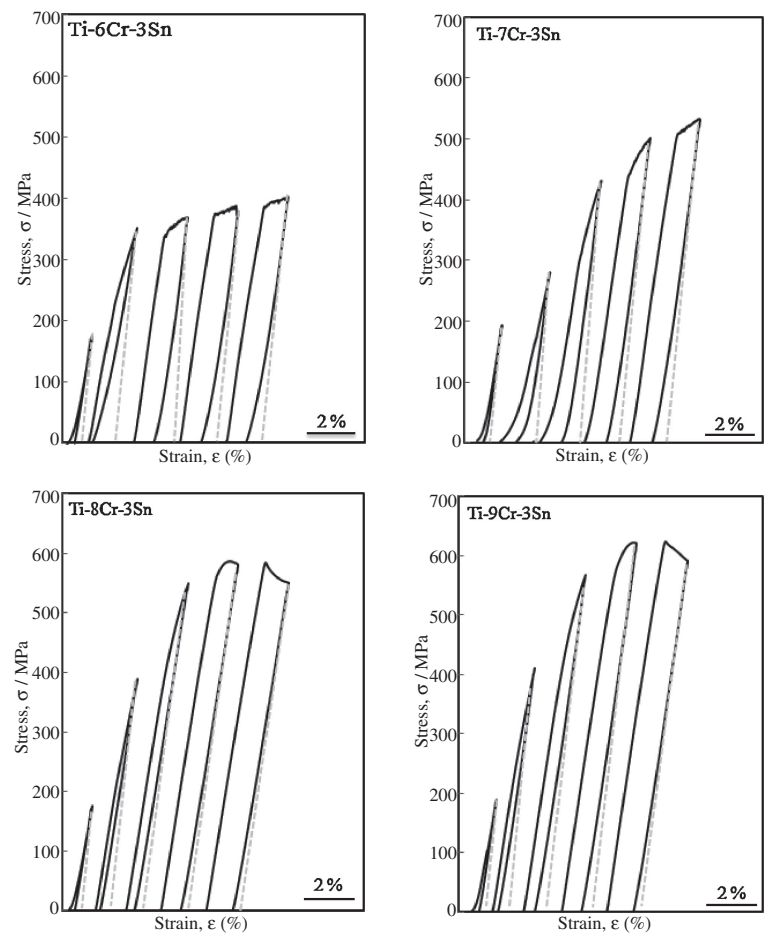

Fig. 10 Cyclic loading-unlaoding curves of $\mathrm{Ti}-x \mathrm{Cr}-3 \mathrm{Sn}$ alloys (1st 5 cycles).

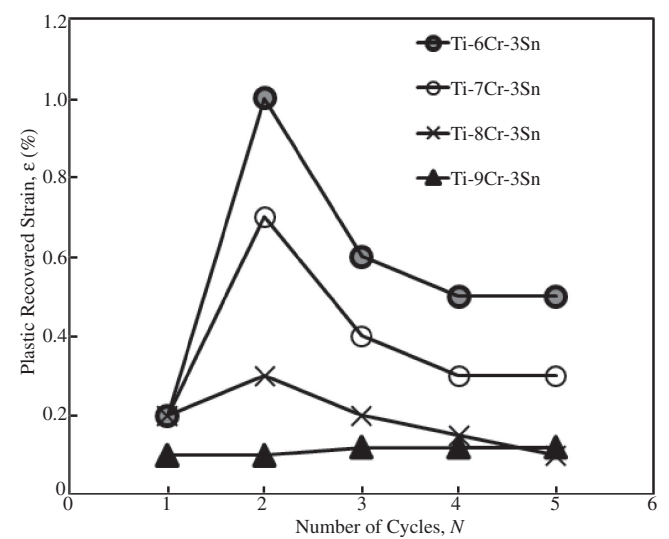

Fig. 11 Plastic recovered strain vs. number of cycles of Ti-xCr-3Sn alloys.

during mechanical loading. So during unloading, some fraction of deformed martensite would revert back to twinned martensite. It was given ${ }^{34)}$ that dislocations introduced during deformation change the energy state in martensite variant. So martensite variant in high energy state reverts to low energy state variants upon unloading, resulting into shape recovery (pseudoelasticity). Plastic recovered strain of Ti- $x \mathrm{Cr}-3 \mathrm{Sn}$ alloys in Fig. 11 has decreased with increasing number of cycles due to permanent slip deformation along with twinning. Permanent deformation due to slip would increase the obstacles to martensite reorientation upon unloading. Reverse transformation path would be affected due to slip. ${ }^{33)}$ Decrease of pseudoelastic recovered strain with increasing $\mathrm{Cr}$ content (Fig. 11) was again due to slip as dominant deformation mechanism (Fig. 6) instead of twinning (Fig. 5) and stabilization of $\beta$ phase (Fig. 8).

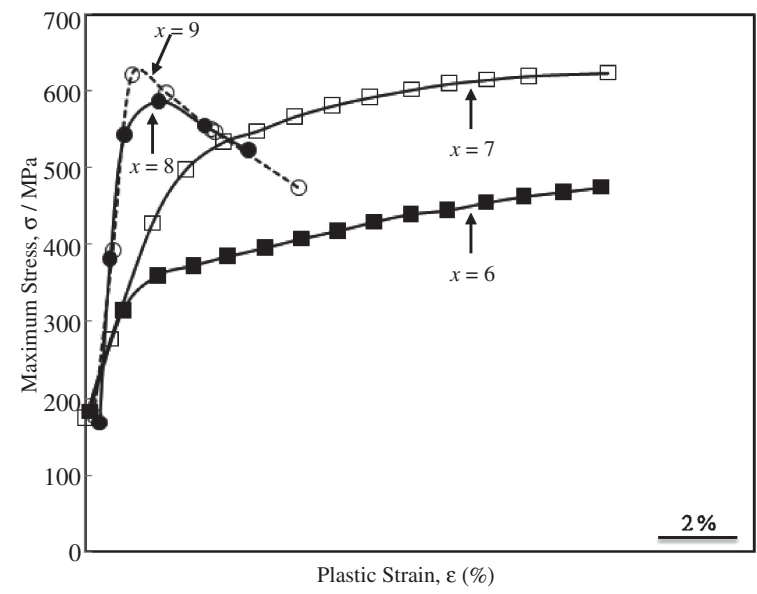

Fig. 12 Maximum stress vs. plastic strain of Ti- $x \mathrm{Cr}-3 \mathrm{Sn}$ alloys.

Maximum applied stress vs. plastic strain per cycle for first fifteen cycle test results are given in Fig. 12. Ti-6Cr-3Sn and $\mathrm{Ti}-7 \mathrm{Cr}-3 \mathrm{Sn}$ alloy specimens did not fracture for first fifteen cyclic loading-unloading cycles showing the ductile behavior. However Ti-8Cr-3Sn and Ti-9Cr-3Sn alloy specimens fractured before first fifteen cyclic loading-unloading cycles showing that ductility was reduced due to slip as dominant deformation mechanism (Fig. 6), $\beta$ phase stabilization (Fig. 8) and solid solution strengthening. From Fig. 12, there was slow increase in maximum stress/cycle (e.g. low work hardening rate) for $\mathrm{Ti}-6 \mathrm{Cr}-3 \mathrm{Sn}$ and $\mathrm{Ti}-7 \mathrm{Cr}-$ $3 \mathrm{Sn}$ alloys that again indicate the transformation of metastable $\beta$ phase to stress induced martensite. Sharp increase in maximum stress/cycle (e.g. high work hardening rate) for Ti8Cr-3Sn and Ti-9Cr-3Sn alloys showed the slip as dominant deformation mechanism as due to slip, dislocation density would increase in each successive cycle and so more applied stress would require for further deformation. Results of Fig. 12 are also in accordance with tensile test results given in Fig. 3, where 7, 8 and 9 mol\% Cr added Ti-3Sn alloys have higher UTS and low fracture strain as compare to $6 \mathrm{~mol} \% \mathrm{Cr}$ added Ti-3Sn alloy due to solid solution strengthening, $\beta$ phase stabilization and change of deformation mode from twinning to slip with increasing $\mathrm{Cr}$ content.

\section{Shape Memory Effect Measurement}

Shape memory effect measurement results are given in Fig. 13. Recovery ratio due to shape memory effect $\left(R_{\mathrm{SME}}\right)$ was measured using following equation.

$$
R_{\mathrm{SME}} \%=\left(\varepsilon_{\mathrm{S}}-\varepsilon_{\mathrm{r}} / \varepsilon_{\mathrm{s}}\right) \times 100
$$

where $\varepsilon_{\mathrm{s}}$ is surface strain after bending deformation and $\varepsilon_{\mathrm{r}}$ is residual surface strain after heating. It was investigated that among the developed alloys, Ti-6Cr-3Sn alloy showed maximum recovery ratio due to shape memory effect $(58 \%)$ that was related to reverse transformation of stress induced martensite to parent $\beta$ phase on heating. Shape memory effect has decreased with greater than $6 \mathrm{~mol} \%$ addition of $\mathrm{Cr}$ in $\mathrm{Ti}$ $x \mathrm{Cr}$-3Sn alloys due to stabilization of $\beta$ phase (Fig. 8) and also due to slip as dominant deformation mechanism (Fig. 6) that hinders the reverse transformation of martensite. ${ }^{33)}$ Results of shape memory effect were in accordance with 


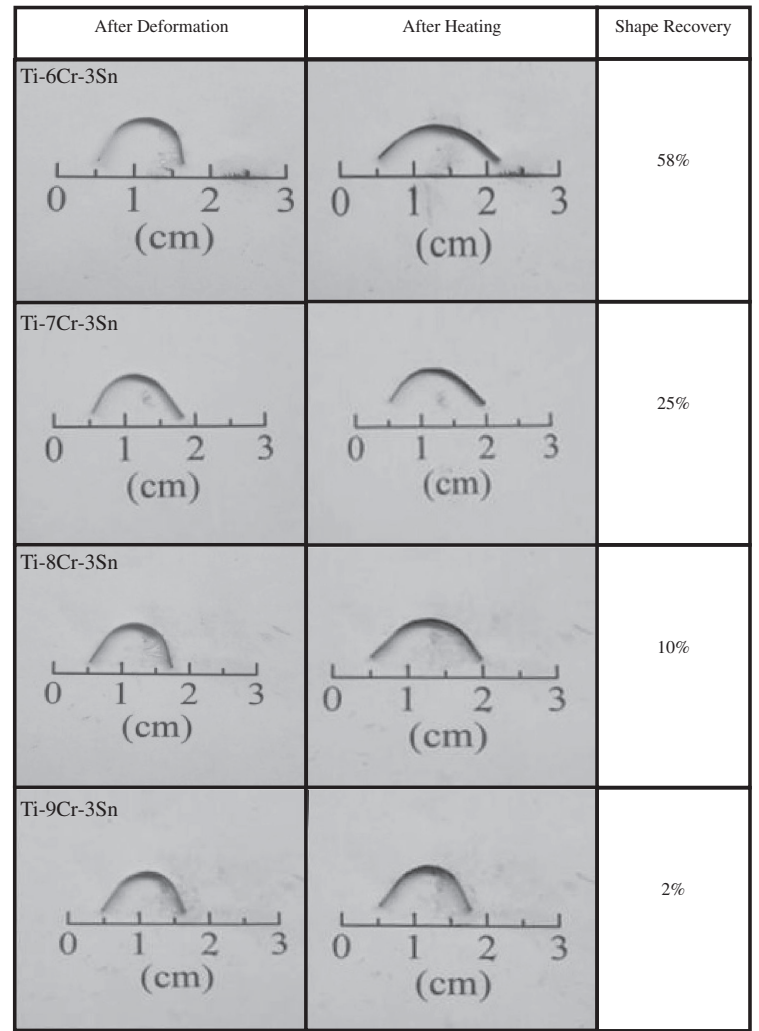

Fig. 13 Shape memory test results of Ti- $x \mathrm{Cr}-3 \mathrm{Sn}$ alloys.

results of pseudoelasticity and tensile test results where Ti$6 \mathrm{Cr}-3 \mathrm{Sn}$ alloy showed maximum pseudoelastic response and maximum ductility among the developed $\mathrm{Ti}-x \mathrm{Cr}-3 \mathrm{Sn}$ alloys.

\section{Conclusion}

Among the developed Ti- $x \mathrm{Cr}-3 \mathrm{Sn}$ alloys, Ti-6Cr-3Sn alloy showed maximum ductility ( $41 \%$ fracture strain), maximum $(58 \%)$ recovery ratio due to shape memory effect and maximum pseoudoelastic response due to stress induced martensitic transformation and twinning deformation mode. UTS has increased and fracture strain, shape memory effect and pseoudoelastic response has decreased with greater than $6 \mathrm{~mol} \%$ addition of $\mathrm{Cr}$ in $\mathrm{Ti}-x \mathrm{Cr}-3 \mathrm{Sn}$ alloys due to $\beta$ phase stabilization, solid solution strengthening and slip as dominant deformation mechanism. Among developed $\mathrm{Ti}-x \mathrm{Cr}$ $3 \mathrm{Sn}$ alloys, Ti-6Cr-3Sn alloy has potential for biomedical applications.

\section{Acknowledgements}

This work was partially supported by a Grant-in-Aid for Fundamental Scientific Research Kiban B (No. 20360310, 2008-2010 and No. 21390522, 2009-2011), and the Global COE program from the Ministry of Education, Culture, Sports, Science and Technology (MEXT) Japan. This work was also partially supported by Funding Program for Next Generation World-Leading Researchers \#LR015 (20112013) from Japan Society for the Promotion of Science.

\section{REFERENCES}

1) P. Filip, J. Lausmaa, J. Musialek and K. Mazanec: Biomater. 22 (2001) 2131-2138.

2) K. Yokoyama, K. Hamada, K. Moriyama and K. Asaoka: Biomater. 22 (2001) 2257-2262.

3) H. Hosoda, Y. Fukui, T. Inamura, K. Wakashima, S. Miyazaki and K. Inoue: Mater. Sci. Forum 426 (2003) 3121-3126.

4) H. Y. Kim, Y. Ikehara, J. I. Kim, H. Hosoda and S. Miyazaki: Acta Mater. 54 (2006) 2419-2429.

5) M. Geetha, A. K. Singh, R. Asokamani and A. K. Gogia: Prog. Mater. Sci. 54 (2009) 397.

6) Y. Al-Zain, H. Y. Kim, H. Hosoda, T. H. Nam and S. Miyazaki: Acta Mater. 58 (2010) 4212-4223.

7) W. F. Ho, C. P. Ju and J. H. Chern Lin: Biomater. 20 (1999) 21152122.

8) E. Cheal, M. Spector and W. Hayes: J. Orthop. Res. 10 (1992) 405422.

9) M. Long and H. J. Rack: Biomater. 19 (1998) 1621-1639.

10) Y. Horiuchi, T. Inamura, H. Y. Kim, S. Miyazaki, K. Wakashima and H. Hosoda: Mater. Trans. 47 (2006) 1209-1213.

11) Y. W. Chai, H. Y. Kim, H. Hosoda and S. Miyazaki: Acta Mater. 57 (2009) 4054-4064.

12) Y. Horiuchi, T. Inamura, H. Hosoda, K. Wakashima, H. Y. Kim and S. Miyazaki: Mater. Sci. Eng. A 438-440 (2006) 830-834.

13) K. Masumoto, Y. Horiuchi, T. Inamura, H. Hosoda, K. Wakashima, H. Y. Kim and S. Miyazaki: Mater. Sci. Eng. A 438-440 (2006) 835838.

14) T. Inamura, Y. Kinoshita, J. I. Kim, H. Y. Kim, H. Hosoda, K Wakashima and S. Miyazaki: Mater. Sci. Eng. A 438-440 (2006) 865 869.

15) H. Saito, T. Inamura, K. Wakashima, H. Hosoda and S. Miyazaki: Proc. Inter. Conf. Shape Memory and Superelastic Technologies, (ASM Intl., OH, USA, 2008) pp. 565-570.

16) G. Lutjering and J. C. Williams: Titanium, (1st edition Springer publisher Germany, 2003) pp. 13-40.

17) S. Miyazaki, H. Y. Kim and H. Hosoda: Mater. Sci. Eng. A 438-440 (2006) 18-24.

18) M. Tahara, H. Y. Kim, H. Hosoda and S. Miyazaki: Acta Mater. 57 (2009) 2461-2469.

19) Y. Al-Zain, H. Y. Kim, T. Koyano, H. Hosoda, T. H. Nam and S. Miyazaki: Acta Mater. 59 (2011) 1464-1473.

20) W. F. Ho, T. Y. Chiang, S. C. Wu and H. C. Hsu: J. Alloy. Compd. 468 (2009) 533-538.

21) M. Ikeda and S. Komatsu: J. Japan Inst. Light Metals 55 (2005) 582586.

22) D. Sugano and M. Ikeda: Mater. Sci. Eng. C 25 (2005) 377-381.

23) W. F. Ho, C. H. Pan, S. C. Wu and H. C. Hsu: J. Alloy. Compd. 472 (2009) 546-550.

24) Y. Kusano, T. Inamura, H. Kanetaka, S. Miyazaki and H. Hosoda: Mater. Sci. Forum 654-656 (2010) 2118-2121.

25) Y. Kusano, T. Inamura, H. Hosoda, K. Wakashima and S. Miyazaki: Adv. Mater. Res. 89-91 (2010) 307-312.

26) W. F. Ho, T. Y. Chiang, S. C. Wu and H. C. Hsu: J. Alloy. Compd. 468 (2009) 533-538.

27) T. Maeshima and M. Nishida: Mater. Trans. 45 (2004) 1096-1100.

28) Y. L. Hao, S. J. Li, S. Y. Sun and R. Yang: Mater. Sci. Eng. A 441 (2006) 112-118.

29) E. Takahashi, T. Sakurai, S. Watanabe, N. Masahashi and S. Hanada: Mater. Trans. 43 (2002) 2978-2983.

30) Y. Fukui, T. Inamura, H. Hosoda, K. Wakashima and S. Miyazaki: Mater. Trans. 45 (2004) 1077-1082.

31) S. Doi, M. Ikeda and M. Ogawa: Proc. 11th World Conference on Titanium, Vol. 1, (2003) pp. 399-402.

32) T. Inamura, Y. Fukui, H. Hosoda, K. Wakashima and S. Miyazaki: Mater. Trans. 45 (2004) 1083-1089.

33) G. Tan and Y. Liu: Intermetallics 12 (2004) 373-381.

34) Y. Yamabe-Mitarai, T. Hara, S. Miura and H. Hosoda: Intermetallics 18 (2010) 2275-2280. 